\title{
KNOWLEDGE SPILLOVERS FROM FDI: A CRITICAL REVIEW FROM THE INTERNATIONAL BUSINESS PERSPECTIVE
}

This is the post-print version of Perri, A., \& Peruffo, E. (2016). Knowledge spillovers from FDI: a critical review from the international business perspective. International Journal of Management Reviews, 18(1), 3-27. (https://doi.org/10.1111/ijmr.12054). Please refer to the published version and also note that this version might differ slightly from the published version. 